\title{
ENTREPRENEUR
}

Jurnal Bisnis Manajemen Dan Kewirausahaan

Program Studi Manajemen Fakultas Ekonomika dan Bisnis Universitas Majalengka

Published every January and July e-ISSN : (Proses), p-ISSN: 2723-1941

Available online htts://ejournal.unma.ac.id/index.php/entrepreneur

\section{Pengaruh Kompensasi dan Budaya Kerja \\ Terhadap Produktivitas Kerja Karyawan \\ Pada Perusahaan Kecap Segi Tiga Majalengka}

\section{Eli Achmad Mahiri}

Fakultas Ekonomika dan Bisnis Universitas Majalengka

e-mail : eliachmadmahiri@ gmail.com

ABSTRACT
The purpose of this study was to determine compensation, work culture, work productivity of
employees at Segi Tiga Majalengka Company. The large influence of compensation influence
on employee work productivity at Segi Tiga Segi Tiga Majalengka Company, has a big
influence on the influence of work culture on employee work productivity at Segi Tiga Segi
Tiga Majalengka Company, and to know the big influence of influence and culture on
employee work productivity at Segi Tiga Majalengka Company.
The method used is a survey method with descriptive analysis techniques and verification. The
data technique was carried out by interviewing, presenting a questionnaire, and studying
literature. The validity test is done by comparing the Corrected Item - Total Correlation value
with the r table value and reliability testing using the Croncbach Alpha formula. The data
analysis design used Data Normality Test Analysis, Determination Coefficient Analysis, t test
and test.
The results of this study indicate that compensation has a significant effect on employee
productivity. Work culture has an effect but not significantly on employee work productivity.
Compensation and work culture together have a significant effect on employee work
productivity.
Keywords:
Compensation; Work Culture; Employee Productivity




\section{ENTREPRENEUR}

Jurnal Bisnis Manajemen Dan Kewirausahaan

Program Studi Manajemen Fakultas Ekonomika dan Bisnis Universitas Majalengka

Published every January and July e-ISSN : (Proses), p-ISSN: 2723-1941

Available online htts://ejournal.unma.ac.id/index.php/entrepreneur

\section{PENDAHULUAN}

Sumber daya manusia (SDM) berperan sangat penting sebagai unsur utama sebuah perusahaan dibandingkan unsur lainnya seperti modal dan teknologi, sebab manusia itu sendiri yang mengendalikan penuh jalannya sebuah perusahaan. Betapapun baiknya sumber daya lain yang dimiliki oleh perusahaan jika tidak dilengkapi dengan kemampuan yang berkualitas dan berkompeten dari sumber daya manusia yang dimilikinya. Kemampuan yang berkualitas dan berkompeten dari sumber daya manusia itulah yang akan menjadi persaingan ketat dalam menentukan kemajuan sebuah perusahaan di masa yang akan datang.

Mengelola perusahaan bukanlah sesuatu hal yang mudah, banyak hambatan yang mungkin akan dihadapi dalam mewujudkan perusahaan yang berkualitas dan berkompeten, terutama mengelola manusia di dalam perusahaan. Pengelolaan sumber daya manusia dalam perusahaan menjadi makin terasa penting karena sumber keberhasilan perusahaan di masa yang akan datang ditentukan oleh seberapa baik perusahaan mengelola sumber daya manusia yang dimiliki. Keberadaan manajemen sumber daya manusia dalam suatu perusahaan bertujuan untuk meningkatkan kontribusi karyawan terhadap organisasi dalam rangka mencapai tujuan perusahaan. Perusahaan yang memiliki sumber daya manusia yang berkualitas dan berkompeten sudah pasti ditunjang dengan kinerja karyawannya yang baik.

Menurut Anoki Herdian Diti (2010) dalam meningkatkan kinerja karyawannya perusahaan menempuh beberapa cara salah satunya melalui pemberian kompensasi yang layak, karyawan diharapkan akan lebih memaksimalkan tanggung jawab atas pekerjaan mereka.

Menurut Nawawi

(2005:319)

"Kompensasi adalah usaha menumbuhkan perasaan diterima (diakui) di lingkungan kerja, yang menyentuh aspek kompensasi dan aspek hubungan antara para pekerja yang satu dengan yang lainnya". Kompensasi atau penghargaan juga diberikan kepada karyawan yang menunjukan loyalitasnya kepada perusahaan, dedikasi tinggi yang dilengkapi dengan disiplin dan budi pekerti yang baik, serta hasil kerja yang baik sesuai dengan tujuan yang akan dicapai perusahaan. Dampak positif dari kompensasi juga dapat membantu karyawan dalam meningkatkan kesejahteraan hidupnya. Dalam konsep manajemen, kompensasi merupakan salah satu cara yang tepat untuk lebih meningkatkan budaya kerja di dalam perusahaan.

Budaya kerja dalam organisasi yang dianut oleh pimpinan perusahaan dan diimplementasikan oleh karyawan menjadi perilaku karyawan yang kemudian menentukan arah keberhasilan suatu perusahaan dalam meningkatkan produktivitas perusahaan.

Salah satu faktor yang mendorong produktivitas yaitu budaya kerja. Menurut Triguno (2004:1) budaya kerja adalah nilai-nilai yang menjadi kebiasaan dan bermula dari adat-istiadat, agama, norma dan kaidah yang menjadi keyakinan pada diri pelaku kerja atau organisasi. Dengan membentuk budaya yang cocok antar angota dalam perusahaan, akan lebih 


\section{ENTREPRENEUR}

Jurnal Bisnis Manajemen Dan Kewirausahaan

Program Studi Manajemen Fakultas Ekonomika dan Bisnis Universitas Majalengka

Published every January and July e-ISSN : (Proses), p-ISSN: 2723-1941

Available online htts://ejournal.unma.ac.id/index.php/entrepreneur

mudah dalam mencapai keberhasilan perusahaan.

Menurut Triguno (1997 : 57) budaya kerja adalah segala falsafah yang didasari oleh pandangan hidup sebagai nilai-nilai yang menjadi sifat, kebiasaan, dan kekuatan pendorong membudaya dalam suatu kelompok organisasi, kemudian tercermin dari sikap menjadi perilaku, kepercayaan, cita-cita, pendapat dan tindakan yang terwujud sebagai kerja atau bekerja. Organisasi yang telah lama berdiri dan berusaha menjaga kelangsungan hidupnya akan berusaha menggali budaya yang spesifik yang menjadi ciri organisasi tersebut dalam menghadapi tajamnya tingkat persaingan dan perkembangan dimasa yang akan datang.

Beberapa penjelasan tersebut dapat menjelaskan bahwa persepsi terhadap kompensasi dan budaya kerja dapat meningkatkan produktivitas kerja karyawan di dalam perusahaan. Jika perusahaan lebih menerapkan Kompensasi dengan baik, maka hal ini akan meningkatkan produktivitas kerja.

Pentingnya sistem kompensasi sebagai salah satu indikator kepuasan dalam bekerja sulit ditaksir, karena pandangan-pandangan karyawan mengenai uang atau kompensasi langsung nampaknya sangat subyektif dan barangkali merupakan sesuatu yang khas dalam industri (Fraser, 1992 : 56). Tetapi pada dasarnya adanya dugaan adanya ketidakadilan dalam memberikan upah maupun gaji merupakan sumber ketidakpuasan karyawan terhadap sistem kompensasi yang pada akhirnya bisa menimbulkan perselisihan dan semangat rendah dari karyawan itu sendiri (Strauss dan Sayles, 1990 : 321).

Sistem kompensasi penting bagi karyawan sebagai individu karena besarnya kompensasi mencerminkan ukuran nilai karya mereka di antara karyawan itu sendiri, keluarga dan masyarakat.

Kemudian program sistem kompensasi juga penting bagi perusahaan, karena hal itu mencerminkan upaya organisasi untuk mempertahankan sumber daya manusia atau dengan kata lain agar karyawan mempunyai loyalitas dan komitmen yang tinggi pada perusahaan (Handoko,1994 : 155).

Objek yang diambil dalam penelitian ini adalah Perusahaan Kecap Segi Tiga yang merupakan perusahaan milik perorangan. Perusahaan Kecap Segi Tiga mulai dirintis sejak tahun 1958 oleh Bapak H. Lukman yang beralamat di JL. Raya Tonjong No. 12 Majalengka. Pada awalnya kecap segitiga dipemerkarsai oleh 3 orang yaitu $\mathrm{H}$ Lukman, Endek dan Aman, dari tiga orang inilah kemudian tercipta tercetus merek Segitiga, proses pembuatan kecap masih menggunakan cara tradisional atau manual, seperti masih menggunakan peralatan tradisional, menggunakan kayu bakar untuk sumber bahan bakar. Bahan baku utama kecap di Perusahaan Kecap Segi Tiga terdiri dari kacang kedelai hitam, gula aren, gula kelapa, dan garam. Bahan baku kecap tersebut diperoleh dari distributor yang sudah jadi pemasok perusahaan, yaitu berasal dari Bandung, Banjar, Cianjur, Cirebon, dan Majalengka.

Produksi kecap segi tiga saat ini sudah mulai meluas dan pemasarannyapun sudah sampai ke beberapa kota di daerah 


\section{ENTREPRENEUR}

\section{Jurnal Bisnis Manajemen Dan Kewirausahaan}

Program Studi Manajemen Fakultas Ekonomika dan Bisnis Universitas Majalengka Published every January and July e-ISSN : (Proses), p-ISSN: 2723-1941

Available online htts://ejournal.unma.ac.id/index.php/entrepreneur

Jawa Barat. Dan menjadi salah satu kecap khas dari Kabupaten Majalengka. Produktivitas kerja pada perusahaan Kecap Segi Tiga Majalengka mengalami fluktuatif, dimana setiap bulannya tidaktetap dalam mencapai target produksi yang ditetapkan oleh perusahaan. Keadaan tersebut perlu adanya analisis untuk mengetahui berbagai faktor dalam mempengaruhi produktivitas karyawan terutama pengaruh dari kompensasi dan budaya kerja dalam perusahaan tersebut.

Berdasarkan uaraian tersebut, penting kiranya membuat suatu model yang membahas produktivitas kerja dengan variable yang mempengaruhinya . untuk itu perlu melakukan analisis mengenai Pengaruh Kompensasi dan Budaya Kerja terhadap Produktivitas Kerja Karyawan pada Perusahaan Kecap Segi Tiga Majalengka.

\section{Rumusan Masalah}

Berdasarkan latar belakang masalah yang dikemukakan maka permasalahan yang dirumuskan dalam penelitian ini adalah sebagai berikut :

1. Bagaimana pengaruh kompensasi terhadap produktivitas kerja pada Perusahaan Kecap Segi Tiga Majalengka.

2. Bagaimana pengaruh budaya kerja terhadap produktivitas kerja pada Perusahaan Kecap Segi Tiga Majalengka.

3. Bagaimana pengaruh kompensasi dan budaya kerja terhadap produktivitas kerja pada Perusahaan Kecap Segi Tiga Majalengka.

\section{Tujuan Penelitian}

Tujuan dari suatu penelitian adalah agar apa yang dilakukan dapat mengarah ke sasaran dan mendapat hasil yang diharapkan. Adapun tujuan penelitian adalah sebagai berikut:

1. Untuk mengetahui pengaruh kompensasi terhadap produktivitas kerja pada Perusahaan Kecap Segi Tiga Majalengka.

2. Untuk mengetahui pengaruh budaya kerja terhadap produktivitas kerja pada Perusahaan Kecap Segi Tiga Majalengka.

3. Untuk mengetahui besarnya pengaruh kompensasi dan budaya kerja terhadap produktivitas kerja pada Perusahaan Kecap Segi Tiga Majalengka.

\section{METODE PENELITIAN}

Metode yang digunakan dalam penelitian ini adalah metode survey dengan pendekatan deskriptif verifikatif. Dengan menggunakan metode penelitian akan diketahui hubungan yang signifikan antara variabel yang diteliti, sehingga menghasilkan kesimpulan yang memperjelas gambaran mengenai objek yang diteliti. untuk maksud tersebut digunakan teknik statistika dengan tahapan :uji normalitas data, analisis deskriptif. Untuk analisis verifikatif menggunakan analisis koefisien determinasi dan uji hipotesis. 


\section{ENTREPRENEUR}

\section{Jurnal Bisnis Manajemen Dan Kewirausahaan}

\section{Program Studi Manajemen Fakultas Ekonomika dan Bisnis Universitas Majalengka}

Published every January and July e-ISSN : (Proses), p-ISSN: 2723-1941

Available online htts://ejournal.unma.ac.id/index.php/entrepreneur

\section{HASIL PENELITIAN DAN \\ PEMBAHASAN \\ Pengaruh Kompensasi Terhadap \\ Produktivitas Kerja Karyawan Pada \\ Perusahaan Kecap Segi Tiga \\ Majalengka}

Berdasarkan hasil perhitungan variabel kompensasi terhadap produktivitas kerja karyawan dengan menggunakan bantuan program SPSS 21, variable kompensasi terhadap produktivitas kerja karyawan adalah 0,568. Artinya variable kompensasi memiliki keeratan hubungan yang sedang serta berpengaruh posiitif terhadap produktivitas kerja karyawan. Hal ini dengan koefisien determinasi yang menunjukan pengaruh kompensasi terhadap produktivitas kerja karyawan sebesar 32,26\% dipengaruhi oleh variabel lain yang tidak diteliti. Hal ini dibuktikan dengan menunjukan nilai koefisien regresi sebesar 0,269. Berdasarkan nilai yang diperoleh dari tabel anova, variabel kompensasi memiliki signifikansi 0,003 < 0,005 dan nilai $t_{\text {hitung }}=1,729>t_{\text {tabel }}=$ 1,689 maka Ho ditolak dan Ha diterima. Sehingga dapat disimpulkan bahwa kompensasi mempunyai pengaruh yang positif dan signifikan terhadap produktivitas kerja karyawan Pada Perusahaan Kecap Segi Tiga Majalengka.

Hasil penelitian ini konsisten dengan penelitian yang dilakukan oleh Zuchri Abdussamad (2014) menyatakan bahwa kompensasi berpengaruh signifikan terhadap produktivitas kerja karyawan. Hasil penelitiannya mengungkapkan bahwa kompensasi secara efektif dan efisien mempunyai pengaruh yang nyata terhadap produktivitas kerja karyawan .
Pengaruh Budaya Kerja Terhadap Produktivitas Kerja Karyawan Pada Perusahaan Kecap Segi Tiga Majalengka

Berdasarkan hasil perhitungan variabel budaya kerja terhadap produktivitas kerja karyawan dengan menggunakan bantuan program SPSS 21, variable budaya kerja terhadap produktivitas kerja karyawan adalah 0,628 . Artinya variable budaya kerja memiliki keeratan hubungan yang sedang serta berpengaruh posiitif terhadap produktivitas kerja karyawan. Hal ini dengan koefisien determinasi yang menunjukan pengaruh kompensasi terhadap produktivitas kerja karyawan sebesar 39,43\% dipengaruhi oleh variabel lain yang tidak diteliti. Hal ini dibuktikan dengan menunjukan nilai koefisien regresi sebesar 0,162. Dengan probabilitas signifikan sebesar $0,000<$ 0,005 dan nilai $t_{\text {hitung }}=1,946>t_{\text {tabel }}=$ 1,689 maka Ho ditolak dan Ha diterima, Sehingga dapat disimpulkan bahwa budaya kerja mempunyai pengaruh yang signifikan terhadap produktivitas kerja karyawan Pada Perusahaan Kecap Segi Tiga Majalengka.

Hasil penelitian ini konsisten dengan penelitian yang dilakukan oleh Nurmaliza (2011) menyatakan bahwa budaya kerja berpengaruh signifikan terhadap produkivitas kerja. Mendukung pendapat Paramita Ndraha (2005:200) yang menyatakan bahwa "melaksanakan budaya kerja mempunyai arti yang sangat dalam, karena akan merubah sikap dan perilaku sumber daya manusia untuk mencapai produktivitas kerja karyawan yang lebih tinggi dalam menghadapi tantangan masa depan". 


\section{ENTREPRENEUR}

\section{Jurnal Bisnis Manajemen Dan Kewirausahaan}

\section{Program Studi Manajemen Fakultas Ekonomika dan Bisnis Universitas Majalengka}

Published every January and July e-ISSN : (Proses), p-ISSN: 2723-1941

Available online htts://ejournal.unma.ac.id/index.php/entrepreneur

Pengaruh Kompensasi dan Budaya

Kerja Terhadap Produktivitas Kerja Karyawan Pada Perusahaan Kecap Segi Tiga Majalengka

Berdasarkan hasil perhitungan variabel kompensasi dan budaya kerja terhadap produktivitas kerja karyawan dengan menggunakan bantuan program SPSS 21, variabel kompensasi dan budaya kerja terhadap produktivitas kerja karyawan adalah 0,610. Menyatakan bahwa variabel kompensasi dan budaya kerja memiliki hubungan yang kuat dan berpengaruh positif terhadap produktivitas kerja karyawan. Hasil dari koefisien determinasi menunjukan pengaruh kompensasi dan budaya kerja terhadap produktivitas kerja karyawan Pada Perusahaan Kecap Segi Tiga Majalengka sebesar 37,21\%. Berdasarkan hasil uji f, diperoleh $\mathrm{f}_{\text {tabel }}$ sebesar 3,28 Karena $f_{\text {hitung }}=23,802>f_{\text {tabel }} 3,28$ maka $\mathrm{H}_{0}$ ditolak, artinya kompensasi dan budaya kerja berpengaruh positif dan signifikan terhadap produktivitas kerja karyawan.

\section{KESIMPULAN DAN IMPLIKASI Kesimpulan}

Berdasarkan hasil penelitian dan analisis data yang telah dilakukan di Perusahaan Kecap Segi Tiga Majalengka mengenai Kompensasi, Budaya Kerja dan Produktivitas Kerja Karyawan, maka penulis mengambil kesimpulan sebagai berikut :

1. Kompensasi berpengaruh dan signifikan terhadap Produktivitas Kerja Karyawan. Artinya dengan semakin tinggi pemberian Kompensasi maka akan semakin tinggi pula Produktivitas Kerja Karyawan. Hal ini dikarenakan dengan kompensasi dapat memenuhi kebutuhannya secara

langsung, terutama kebutuhan
fisiologinya.

2. Budaya Kerja berpengaruh dan signifikan terhadap Produktivitas Kerja Karyawan. Artinya bahwa tinggi rendahnya Produktivitas Kerja Karyawan akan berpengaruh terhadap Budaya Kerja. Hal ini dikarenakan budaya kerja akan merubah sikap dan perilaku sumber daya manusia untuk mencapai produktivitas kerja yang lebih tinggi dalam menghadapi tantangan masa depan.

3. Kompensasi dan Budaya Kerja berpengaruh dan signifikan terhadap Produktivitas Kerja Karyawan. Artinya semakin baik Kompensasi dan Budaya Kerja semakin baik pula Produktivitas Kerja Karyawan. Hal ini dikarenakan kompensasi dan budaya kerja akan terlihat baik bagi karyawan dan manajemen perusahaan serta akan dapat meningkatkan produktivitas kerja karyawan.

\section{Saran}

Berdasarkan hasil penelitian dan pembahasan yang telah dilakukan, penulis memberikan saran yang di harapkan dapat memberikan manfaat dan dapat dijadikan bahan pertimbangan bagi pihak-pihak yang berkepentingan, yaitu:

1. Indikator kompensasi belum sesuai harapan, Perusahaan Kecap Segi Tiga Majalengka diharapkan dapat memperhatikan gaji karyawan, sehingga dapat memenuhi kebutuhan keluarga karyawan.

2. perusahaan lebih memperhatikan dalam setiap langkah yang dilakukan oleh para karyawan, hal tersebut dapat mempertahankan atau memberikan motivasi agar semua karyawan Perusahaan Kecap Segi Tiga Majalengka memiliki perilaku baik yaitu jujur. 


\section{ENTREPRENEUR}

\section{Jurnal Bisnis Manajemen Dan Kewirausahaan}

Program Studi Manajemen Fakultas Ekonomika dan Bisnis Universitas Majalengka Published every January and July e-ISSN : (Proses), p-ISSN: 2723-1941 Available online htts://ejournal.unma.ac.id/index.php/entrepreneur

3. Belum tercapinya target kerja yang diharapkan yang ditetapkan oleh perusahaan. Maka dari itu penulis menyarankan agar perusahaan lebih meningkatkan faktor-faktor yang dapat mempengaruhi target kerja, sehingga produktivitas kerja yang dilakukan oleh para karyawan dapat dimaksimalkan.

\section{DAFTAR PUSTAKA}

Akhmad Barkati. 2013. Pengaruh Lingkungan Kerja dan Etos Kerja Terhadap Kinerja Pegawai (Studi pada Dinas Perikanan dan Kelautan Kabupaten Banjar). Jurnal Kindai Vol. 9 No. 4 Tahun 2013.

Anwar Prabu Mangkunegara. 2005. Evaluasi Kinerja Sumber Daya Manusia, Bandung: Refika Aditama.

Eti Rochaety. 2007. Metode Penelitian Bisnis dengan Aplikasi SPSS. Jakarta: Mitra Wacana Media.

Gujarati, 2003. Ekonometri Dasar. Terjemahan: Sumarno Zain, Jakarta: Erlangga.

Hasibuan, Malayu S.P., 2012. Manajemen Sumber Daya Manusia, Edisi Revisi. Jakarta: PT. Bumi Aksara.

Imam Ghozali. 2007. Statistika Untuk Penelitian. Bandung: Alfabeta.

Nitisemito, Alex S. 2000. Manajemen Personalia. Jakarta: Balai Aksara dan Yudhistira.
Sedarmayanti. 2011. Manajemen Sumber Daya Manusia, cetakan ke empat. Bandung: Refika Aditama.

Sugiyono. 2015. Metode Penelitian Manajemen, cetakan ke empat. Bandung: Alfabeta.

Tjutju Yuniarsih dan Suwatno. 2008. Manajemen Sumber Daya Manusia. Bandung: Alfabeta.

Yunus dan Titien Sukartini. 2013. Manajemen Sumber Daya Manusia. Majalengka: Universitas Majalengka. 